\title{
POLICÍAS, REPRESIÓN Y "LUCHA ANTISUBVERSIVA": EXPLORACIONES SOBRE EL ROL DE LAS POLICÍAS EN EL ACCIONAR REPRESIVO DE LOS AÑOS 70 EN ARGENTINA
}

\author{
Police forces, repression and "contra-subversive fight": explorations about the \\ police forces' role in the repression during the 70's in Argentina
}

\section{Gabriela Águila*}

\section{Resumen}

El artículo explora algunas claves de análisis para estudiar a las policías en el período de mayor intensidad represiva: el problema de la "militarización", la relación entre rutina y novedad en los procedimientos policiales en el contexto de la denominada "lucha antisubversiva", el rol de los d-2 y la territorialidad de la represión. Además de un repaso crítico sobre la bibliografía especializada en la temática, el trabajo utiliza fuentes documentales como causas judiciales, normativa y documentos de la institución, legajos personales, prensa periódica, declaraciones y discursos, entre otros, para reconstruir el caso de la policía de la ciudad de Rosario.

$$
<\text { Policía }><\text { Represión }><\text { Historia reciente }><\text { Argentina }>
$$

\begin{abstract}
The article explores some analytical keys to study the police forces in the period of greatest repressive intensity: the problem of "militarization", the relationship between routine and novelty in police procedures in the context of the so-called "anti-subversive fight", the role of d-2 and the territoriality of repression. In addition to a critical review of the specialized bibliography on the subject, the article uses sources such as court cases, regulations and documents of the institution, personal files, periodical press, statements and speeches, among others, to reconstruct the case of the Rosario police.
\end{abstract}

$$
<\text { Police force }><\text { Repression }><\text { Recent history }><\text { Argentina }>
$$

Recibido: 7/05/2018 //Aceptado: 15/07/2018

La historia argentina del siglo XX está atravesada por la violencia política y el despliegue de la represión estatal y paraestatal. Los recurrentes golpes de Estado y la intervención de las Fuerzas Armadas en la escena política, el autoritarismo y las restricciones a los derechos ciudadanos, la proscripción política (de las organizaciones de izquierda, del peronismo) y la represión hacia los conflictos sociales y laborales,

\footnotetext{
* Doctora en Historia por la Universidad Nacional de Rosario, Argentina, Investigadora Independiente CONICET, con sede en ISHIR (Investigaciones Socio-Históricas Regionales), Profesora Titular, Facultad de Humanidades y Artes, Universidad Nacional de Rosario, gbaguila@gmail.com
} 
Águila. Policías, represión y "lucha antisubversiva": exploraciones sobre el rol de las policías en el accionar...

han sido parte constitutiva de la historia nacional, incrementándose notablemente en la segunda mitad del siglo.

En ese ciclo de violencia política destaca el período abierto hacia fines de los años 60 y caracterizado por una intensa movilización social y un proceso de radicalización de las protestas contra el gobierno dictatorial instalado en 1966, que incluyeron actores, demandas y repertorios de acción múltiples y novedosos en sus contenidos y formas (la activación de los sectores obreros, la creciente agitación entre los sectores medios y universitarios y, finalmente, el surgimiento de las organizaciones político-militares). La escalada represiva estatal y paraestatal desplegada para contrarrestar la insurgencia armada y reducir brutalmente los niveles de conflictividad social y política que recorrió la década de 1970, denotó un contexto de violencia política creciente que tuvo su clímax con la última dictadura militar (marzo de 1976-diciembre de 1983), cuando se implementó un accionar represivo inédito en sus características, dispositivos y escalas (Águila, 2013a).

La violencia política y represiva se ha convertido en clave principal de interpretación de la historia argentina del siglo $\mathrm{XX}$ y, en particular, de la historia del pasado reciente y, como tal, constituye uno de los objetos de estudio y reflexión más transitados por las ciencias sociales y la historiografía. La problemática no sólo ha nutrido la reflexión intelectual y la producción académica sobre la historia reciente, sino también las memorias o relatos construidos sobre ese pasado que se ubican en un espacio público y político más amplio.

Se trata entonces de un tema de indudable centralidad y sobre el que disponemos de un conocimiento amplio, tanto en lo referido a las dinámicas y dispositivos represivos utilizados, en particular en su faz clandestina, como respecto de las víctimas de los crímenes de lesa humanidad y los efectos sociales ampliados del terror de Estado. Sin embargo, este conocimiento exhibe algunos vacíos o limitaciones, entre ellos que el foco ha estado puesto fundamentalmente en el accionar de las Fuerzas Armadas, principales responsables del comando y ejecución de la represión, y menos en las otras fuerzas que desempeñaron un rol significativo en el despliegue represivo de los años 70, tal y como sucedió con la policía.

Considerando el amplio desarrollo de los estudios sobre la policía y, en otra línea, de los estudios sobre la represión y la violencia política que se ha verificado en la Argentina en estos últimos años, en este trabajo me propongo realizar un balance crítico de la bibliografía disponible, reconociendo sus énfasis y vacancias, para luego esbozar algunas claves de análisis respecto del rol cumplido por las policías ${ }^{1}$ en el período de mayor intensidad represiva.

\footnotetext{
1 Utilizo deliberadamente el término en plural, con el objetivo de "definir con nitidez los límites" de mi objeto de estudio (Montero, 2007: 82), registrando la existencia de distintas policías las que, si bien pueden ser agrupadas en el mismo rótulo en virtud de ciertos atributos y funciones que las definen (la preservación del orden público, la prevención y represión del delito), deben ser analizadas considerando sus diferentes jurisdicciones y dependencias (federal, provincial, municipal) y, por ende, sus radios de actuación (en el ámbito urbano, rural, fronterizo) y sus misiones y funciones que incluyen, entre otras cuestiones, a quienes persiguen (Marengo, 2009: introducción). Ello resulta clave para analizar el papel de una institución con una larga historia en un contexto histórico específico y, por varias razones,
} 


\section{Estudiar las policías, estudiar la represión}

En las últimas dos décadas, en las ciencias sociales y la historiografía argentina se han venido desarrollando múltiples líneas de indagación sobre el delito, las cárceles, el castigo y, más específicamente, la policía. Por un lado, existe un conjunto de estudios sobre la policía en perspectiva histórica, en una temporalidad que no suele superar la primera mitad del siglo XX. ${ }^{2}$ Por otro lado, contamos con trabajos provenientes de diversas disciplinas (la antropología social y jurídica, la sociología, el ámbito jurídico o la criminología) que, con preocupaciones heterogéneas, han estudiado a las fuerzas de seguridad y a la policía, con la atención puesta en la violencia institucional desplegada en contextos más recientes. ${ }^{3}$

Nos encontramos entonces ante un campo de estudios de fuerte desarrollo (Ríos, 2014), si bien con algunas notas y vacancias que interesa reseñar. Junto a los diferenciados abordajes en términos disciplinares, hay que señalar que la mayor parte de estos trabajos han puesto el foco en la policía de la provincia de Buenos Aires y en la Policía Federal, excepción hecha de unos pocos análisis sobre las policías en otros espacios provinciales, si bien con distintos énfasis y periodizaciones. ${ }^{4}$ Por otra parte, y en lo que refiere a las temporalidades, una revisión atenta de la literatura académica sobre la temática sorprende por la escasez de trabajos sobre la policía en la segunda mitad del siglo XX y, sobre todo, por la ausencia casi completa de exploraciones sobre la actuación de la policía en el contexto de mayor despliegue represivo del siglo XX, es decir entre los años 60 y $80 .{ }^{5}$

Muchos trabajos académicos centrados en el estudio de la policía han insistido en la "opacidad" de ese objeto de estudio, en las dificultades para analizar a la institución, sus agentes y prácticas en distintos momentos y contextos, entre las que se cuenta el problema del acceso a las fuentes. ${ }^{6}$ Se trata entonces de una situación que denota al objeto y desborda la temporalidad de la Historia reciente o de los estudios sobre la última dictadura.

excepcional, como el que nos ocupa.

2 Entre otros, ver Bohoslavsky, Caimari y Schettini, 2009; Caimari, 2004; Gayol y Kessler, 2002; Barreneche, 2007; Barry, 2010; Galeano, 2007; Pérez, 2009. Para un estado de la cuestión ver Barreneche y Galeano, 2008. También véase el sitio web de Crimen y sociedad. Delito y castigo en perspectiva histórica. Prácticas ilegales, policía, justicia y sistema penitenciario en la Argentina (siglos XIX y XX): http://www.crimenysociedad.com.ar/.

3 Tiscornia, 2000, 2004a, 2004b; Frederic, 2008; Saín, 2008; Sirimarco, 2010; Frederic et al., 2014; Hathazy, 2016. Para los trabajos provenientes del campo jurídico sobre reformas policiales, ver Palmieri, Martínez, Sozzo y Thomas, 2001; Sozzo, 2005; González, 2005. También véase Delito y sociedad. Revista de ciencias sociales (en línea: http://iigg.sociales.uba.ar/revistas-2/delito-y-sociedad/)

4 Cfr. Bohoslavsky, 2009 y 2010; Rafart, 2008; Barreneche, 2008; Barrera, 2014; Bianciotto, 2014; también los textos sobre reformas policiales citados en la nota 3.

5 Similar consideración la encontramos en Eidelman, 2012.

6 Ver por ejemplo Tiscornia, 2004a; Sozzo, 2005: 7; Sirimarco, 2010: introducción. Para una revisión sobre los archivos policiales de la provincia de Buenos Aires ver Barreneche, 2010 y Hathazy, 2010. En otra dirección y para la relación entre archivos policiales, antropología forense y justicia, ver Olmo, 2002. 
Por su parte, en su trabajo sobre la formación policial, Diego Galeano registra otra cuestión que caracteriza a los estudios sobre la policía en América Latina y que interesa en particular en este análisis:
"La literatura académica sobre la policía en Latinoamérica aparece casi siempre de la mano de investigaciones acerca del rol de las fuerzas armadas en sus sistemas políticos. En los debates acerca de la "transición democrática", especialmente durante la década de 1980, el poder policial no recibió suficiente atención, al quedar opacado por la gran preocupación depositada en la cuestión militar. La policía, sin embargo, fue encontrando un lugar en la agenda democrática, cuando el margen de autonomía de sus prácticas se hizo visible a través de numerosos casos de corrupción y violencia institucional. Al ritmo de las primeras reformas institucionales se planteó la necesidad de desarticular el "modelo militarizado", algo que se consideraba un elemento común a las policías latinoamericanas" (Galeano, 2007: 114).

En esta dirección, los balances o estados de la cuestión disponibles abundan sobre el impacto del terrorismo de estado sobre las fuerzas de seguridad y las policías, señalan la centralidad de la problemática en las políticas estatales y en los estudios académicos a partir de la transición democrática, exploran las continuidades y la persistencia hasta la actualidad de dispositivos y prácticas instalados en los años dictatoriales y en la militarización de las fuerzas de seguridad, sin dar cuenta de que carecemos de estudios en profundidad sobre las policías en el período que se extiende entre fines de los años 60 y principios de los 80 .

A mi juicio, esta (relativa) ausencia de investigaciones sobre el rol específico de las policías en el período de mayor intensidad represiva es atribuible no sólo a miradas atravesadas por las agendas y urgencias de la transición democrática o por la necesidad de explicar (y reducir) los niveles de violencia institucional a través de políticas estatales específicas, sino que también deben inscribirse en perspectivas de análisis que enfatizaron la innegable centralidad de las Fuerzas Armadas (FFAA) en el ejercicio de la represión, y que han visto el accionar de las otras fuerzas represivas solo en el marco de la militarización -o la "subsunción" de dichas agencias a las FFAA-.

Ello ha contribuido a limitar la indagación en profundidad sobre el rol que asumieron las policías en aquel contexto, de dar cuenta de los sustentos normativos e ideológicos del accionar policial durante la denominada "lucha antisubversiva", de las modalidades específicas de ese accionar, de su involucramiento en tramas y circuitos represivos y de las relaciones intra e interfuerzas entre agencias represivas estatales, en distintas escalas y contextos.

Si los estudios sobre las policías han tenido un desarrollo notable en los últimos años, no menos prolífica ha sido la línea de estudios sobre la represión en la 
historia reciente argentina (Águila, 2017), aunque debe señalarse que los dos campos de indagación se han desenvuelto en paralelo y casi sin intersecciones uno con el otro.

En contraste con los avances registrados respecto de otras agencias represivas -las FFAA, en particular el Ejército (Mazzei, 2012; Pontoriero, 2015, 2016 y 2017; D’Antonio, 2016; Águila et al., 2017) y, en menor medida, la Armada (Barragán y Zapata, 2015; Barragán e Iturralde, 2017), las cárceles (D’Antonio y Eidelman, 2010; Garaño, 2009 y 2010), los servicios de inteligencia (Kahan, 2008; Águila, 2013b; Marengo, 2015; Montero, 2016) o los trabajos que reconstruyen el funcionamiento de otras instituciones y espacios burocráticos estatales (Villalta, 2012; Sarrabayrouse Oliveira, 2011; Regueiro, 2011)-, prácticamente no contamos con estudios específicos sobre las policías.

No podría decirse, sin embargo, que su importancia pase inadvertida o que el tema no haya sido tratado, si bien en general se lo ha hecho de manera lateral y no poniéndolo en el centro de análisis: a través de la reconstrucción de tramas y circuitos represivos específicos, legales y extralegales o atendiendo al rol de las policías en la represión del conflicto social y político (Maneiro, 2005; Águila, 2008; Paiaro, 2010 y 2015; Scatizza, 2015 y 2017; Águila, Garaño \& Scatizza, 2016: $3^{\circ}$ parte; Rodríguez Agüero, 2010; Margaria y Schnyder, 2017). ${ }^{7}$

Desde mi perspectiva, y tal como se ha verificado en el caso de otros ámbitos de acción estatal y otras agencias represivas, el estudio de las policías contribuiría a avanzar y profundizar el conocimiento que tenemos sobre algunos de los temas centrales en esta línea de estudios. Entre ellos, a la problematización sobre las periodizaciones o temporalidades del ejercicio represivo y a dar cuenta de sus continuidades y rupturas en la historia reciente (antes, durante y después de la última dictadura); así como permitiría registrar con mayor precisión las variaciones locales y regionales del ejercicio de la represión, la configuración de tramas y circuitos represivos específicos y la articulación entre dispositivos represivos legales y extra-legales, ayudando a complejizar tanto como a desarmar visiones monolíticas de la acción represiva estatal.

\section{Algunas claves para explorar el rol de las policías en la "lucha antisubversiva"}

Plantearé a continuación cuatro vías de entrada para estudiar a las policías en el contexto de mayor intensidad represiva, a partir de un análisis de caso en profundidad, el de la policía rosarina. La elección de un caso específico de análisis obedece a un conjunto de consideraciones, por un lado a las ventajas que posee el conocimiento minucioso de la actuación de la policía en ese ámbito urbano, pero también al hecho de que existen importantes carencias en la información disponible sobre las policías provinciales en el período bajo estudio -e investigarlas pormenorizadamente excede largamente las aspiraciones de este trabajo-, lo que inviabiliza el análisis comparado o avanzar en una instancia de síntesis. Con todo, el estudio de caso permite sustentar la validez o pertinencia de dichas claves para el estudio de las policías en aquel contexto

Son excepciones los trabajos de Barreneche, 2011 y 2012; Eidelman, 2010 y 2012 y algunos de los textos contenidos en el reciente dossier "La formación policial en Río Negro" (Pérez et al., 2017). 
Águila. Policías, represión y "lucha antisubversiva": exploraciones sobre el rol de las policías en el accionar...

específico, quedando planteada la posibilidad de ponerlas a prueba y/o validarlas para otros casos.

1) La primera cuestión es una advertencia de orden teórico-metodológico y refiere a la difusión y uso en general acrítico de una categoría fuertemente instalada en los estudios sobre las policías en América Latina: la militarización. En general, con ella se alude al papel central cumplido por las FFAA en el mantenimiento del orden interno tanto como a la estructura militarizada de las policías en diversos países de la región. En palabras de uno de los especialistas más citados, la militarización es la "tendencia a involucrar a fuerzas militares más profundamente en funciones policiales e integrar entrenamiento y una disciplina de tipo militar en las fuerzas policiales" (Bailey, 2010). Por su parte, dicho fenómeno de militarización de las policías aparece asociado al de policialización de las FFAA, es decir a la intervención de éstas en la seguridad interior (en términos teóricos, reservada a la policía) y, eventualmente, a la adopción por parte de los militares de procedimientos y métodos brutales asociados al accionar policial (Dammert y Bailey, 2005; Dammert, 2005: 55-56).

Esta dimensión ha sido insistentemente planteada también para el caso de la Argentina, vinculada a los recurrentes golpes de Estado y a la injerencia de las FFAA en las instituciones policiales. Tal proceso de militarización se habría operado a través del nombramiento de militares en servicio activo al frente de las instituciones policiales (la Policía Federal y las policías provinciales), de la adopción del modelo de organización militar (por ejemplo, en el escalafonamiento y la cadena de mandos) o, más en general, de la subordinación de las policías a las estrategias y actividades represivas militares. En esta dirección, la militarización ha sido identificada con la estructura jerarquizada y centralizada de la institución policial, con el proceso de profesionalización de las policías o, incluso, con la obediencia y el cumplimiento de órdenes. Y, finalmente, la participación de la policía en la persecución y represión del "enemigo político" y el involucramiento en violaciones masivas a los derechos humanos en los años de la última dictadura serían la prueba palpable del proceso de militarización. ${ }^{8}$

Más allá de una tendencia muy visible en la bibliografía a la generalización para el caso argentino de explicaciones provistas por las obras de referencia teórica y de la eventual confusión entre aquel proceso y la profesionalización de las fuerzas policiales, resulta llamativa la disparidad de criterios y contenidos asignados en los estudios disponibles a la militarización de las policías.

Vinculado con ello, señalo dos perspectivas recurrentes: el consignar la existencia de un proceso de militarización sin demasiada explicitación, descripción o análisis, que convoca a preguntarse cómo y cuando se verificó y sobre los sentidos teóricos e históricos del proceso y, alternativamente, una interpretación de la militarización como

\footnotetext{
8 Ver, entre otros, Gayol y Kessler, 2002: Introducción; Andersen, (2002: 106 y ss); Barreneche, (2010); Eidelman, (2010: 46-47); Sirimarco, (2009: 133-135); Saín, (2008: 265); Sozzo, (2016). De allí la necesidad en el contexto democrático de "desmilitarizar" a las fuerzas de seguridad, al respecto ver Abregú, Palmieri y Tiscornia, (1998); Saín, (1997).
} 
subordinación o "subsunción" completa y sin matices de las policías a las FFAA, que no necesariamente registra las transformaciones que se verificaron en la relación entre FFAA y policías, así como sus modulaciones, en particular en la segunda mitad del siglo XX. ${ }^{9}$

No es mi objetivo negar la existencia de tal proceso u obviar la articulación existente entre las FFAA y las policías - que sin dudas precede al despliegue represivo de los años 70 y se fortalece en dicho contexto-, sino plantear como hipótesis de trabajo que la militarización como clave analítica fundamental tiende a borrar la existencia tanto las autonomías (relativas) de algunas agencias -y entre ellas de las policías- como las tensiones que se verificaron entre ellas.

En lo que refiere a mi caso de análisis, sólo consignaré que -como sucedió en otras provincias- los jefes de la policía de la provincia de Santa Fe fueron militares durante gran parte de la segunda mitad del siglo $\mathrm{XX}^{10}$ y hasta la transición democrática; y que la estructura centralizada y verticalizada de la policía provincial, propia de una institución represiva como esa, se consolidó bastante antes de los años 60-70. ${ }^{11}$ En tal sentido, ambos rasgos serían constitutivos de la institución policial en una temporalidad amplia, por lo que debería relativizarse su centralidad (o, al menos, ponerse en debate) para dar cuenta de las relaciones entre las FFAA y las policías en el período de mayor intensidad represiva.

Una cuestión conexa, más acotada temporalmente, y muchas veces identificada con la militarización fue el denominado "control operacional" que las FFAA ejercieron sobre las policías y otras fuerzas de seguridad en particular en los años 70. ${ }^{12}$ Durante dicho período, las fuerzas policiales fueron colocadas bajo "control operacional" de las FFAA en dos ocasiones: en 1971-72 y a partir de octubre de 1975, en ambos momentos

9 Una excepción notable a esta tendencia es el reciente trabajo de Muzzopappa (2017). También véase Hathazy, (2016).

${ }^{10}$ Esto no fue privativo de la policía de Santa $\mathrm{Fe}$, ya que durante las décadas posperonistas en otras jurisdicciones provinciales los jefes de policía también fueron militares, y lo mismo sucedió en la Policía Federal (Andersen, 2002: 168).

${ }^{11}$ Analizar el proceso de profesionalización de la policía santafesina en el siglo XX excede largamente los objetivos de este trabajo, por lo que referimos al estudio de Barreneche y Galeano, que han estudiado tal cuestión poniendo el foco en la policía de Buenos Aires, si bien registraron lo sucedido en las policías provinciales: "A mediados de la década de 1940, a partir de la llegada del peronismo al poder, comenzó una fase madura del proceso de profesionalización de las fuerzas policiales (...) En cuanto a las policías provinciales, las claves del cambio de la organización policial fueron, en general, la centralización, el reforzamiento de la autoridad jerárquica y el afianzamiento del sistema de escalafones, todo ello conforme a los lineamientos del orden y la doctrina militar.(...) la profesionalización de las fuerzas policiales, traducida en términos de refracción a los contactos con la sociedad civil, tenía una fuerte inspiración militar para alejar a la policía de la influencia que sobre ella habían ejercido políticos y dirigentes sectoriales y locales inescrupulosos, especialmente durante la década del treinta" (Barreneche y Galeano, 2008: 87-88).

${ }^{12}$ Según la normativa castrense, vigente en el período, el control operacional "otorga la autoridad con limitaciones sobre las fuerzas dependientes, para el cumplimiento de la misión impuesta. El control operacional comprende la determinación de las relaciones de comando de las fuerzas dependientes y la imposición de misiones. No incluye a los servicios para apoyo de combate, ni lo referente a la disciplina, organización e instrucción". En Ejército Argentino, RFD-99-01, Terminología castrense de uso en la fuerza Ejército. (1969). Parte Primera: 106. 
Águila. Policías, represión y "lucha antisubversiva": exploraciones sobre el rol de las policías en el accionar...

con el objetivo declarado de "luchar contra la subversión" y en contextos en donde era la policía quien venía llevando adelante el accionar represivo contra los "delincuentes subversivos". De resultas de ello, se operó un proceso de subordinación a las directivas y mandos militares, si bien la policía no dejó de realizar tales tareas lo que resultó, en particular en los años de la última dictadura, en eventuales tensiones entre el comando militar y las policías.

Estas disputas o conflictos, cuando existieron, en general no se ventilaron públicamente. No tenemos registro, por ejemplo, de manifestaciones de jefes policiales reclamando para sí el control de la seguridad interna y sólo escasas referencias a declaraciones de altos jefes militares aludiendo -entre líneas- a la existencia de ciertas tensiones entre las fuerzas. ${ }^{13}$ Por el contrario, contamos con relatos y denuncias de víctimas de la represión así como testimonios de "arrepentidos" recogidos en los años 80 , que dan cuenta de conflictos o malestar entre cuadros militares o policiales en el contexto de mayor intensidad represiva, ${ }^{14}$ así como otros hechos similares consignados por trabajos de índole periodística. ${ }^{15}$

\footnotetext{
${ }^{13}$ Me refiero al discurso pronunciado en mayo de 1978 por el ministro del interior Gral. Eduardo A. Harguindeguy, en ocasión de la inauguración del $\mathrm{V}^{\circ}$ Congreso de Jefes de Policía Nacionales y Provinciales (Diario El Litoral, 03/05/78). Ante un público de oficiales y jefes de policía, se refirió al proceso de "interpenetración" entre las fuerzas en el contexto de la "lucha antisubversiva" y a las consecuencias que ello generó, en particular en la policía. Allí afirmó: “...cuando las FFAA y en particular el Ejército, se hicieron cargo de la lucha contra la subversión, las fuerzas policiales fueron puestas bajo el control operacional de las autoridades militares (...) Sin embargo, como en toda guerra prolongada se produjo una "Interpenetración" entre sus actores (...) también se produjo entre las Fuerzas Armadas, en especial en Ejército y las Fuerzas Policiales, que operaron y operan en estrecha vinculación (...) Este fenómeno se acentuó por el hecho de que Jefes de las Fuerzas Armadas, en actividad, se hicieron cargo de las Jefaturas de las Policías Provinciales. Esta medida contribuyó a mejorar rápidamente el encuadramiento de las policías, pero a su vez produjo un fenómeno de militarización en ellas. Esta falta de nitidez dentro de las Instituciones no es buena (...)". Más adelante, el Ministro del interior aludió a la existencia de comportamientos policiales reñidos con la ley y las normas: "la crisis que transitamos y la lucha contra la subversión impusieron procedimientos de excepción. Además, a su amparo floreció una suerte de matonismo y de prepotencia inaceptables". Convenio Policial Argentino (1978), en Causa Feced, cuerpo 12, fs. 346/50. A propósito de ese discurso, Andersen señala que en una entrevista realizada años más tarde, Harguindeguy afirmó: "La policía se fue de los carriles y empezó a incursionar en lo militar (...) Estaban tan juntos que parecían una sola fuerza" (Andersen, 2002: 288). Aunque el discurso pueda resultar inusual -en tanto constituye una declaración pública de una figura principal de la dictadura cuestionando a las fuerzas de seguridad y en un contexto donde el gobierno militar contaba todavía con un amplio margen de maniobra-, resulta congruente con las declaraciones de otros jerarcas del régimen, como el propio Videla, que ya estaban sosteniendo la teoría de la "guerra sucia" y los "excesos" en la "lucha antisubversiva" (Canelo, 2016: cap. 3, passim).

${ }^{14}$ Para el caso de la policía rosarina he analizado las denuncias de algunos detenidos en centros clandestinos durante la última dictadura, así como las declaraciones del ex agente de inteligencia Gustavo Bueno brindada al CELS en los años 80 (Águila, 2016: 352-353). Esta última cuestión se replica en el testimonio del "arrepentido" Rodolfo Peregrino Fernández (ex ayudante del Gral. Harguindeguy) brindado ante la CADHU en 1983, quien relató los conflictos entre el Ministro del Interior y el Primer Cuerpo de Ejército comandado por el Gral. Suárez Mason por el control de la Policía Federal, en Extracto del testimonio presentado a la C.A.D.H.U - Comisión Argentina de Derechos Humanos-, COSOFAM, Barcelona, mayo de 1983, mimeo: 30 y ss. También Andersen, 2002: 272 y ss.

${ }^{15} \mathrm{La}$ existencia de conflictos o disputas entre las fuerzas ha sido consignada por Andersen, quien recurre a entrevistas y testimonios de oficiales de la Policía Federal (2002: 258-259; cap. 7, passim) y también detalla las críticas que realizaba Acdel Vilas a la policía mientras fue comandante del $\mathrm{V}^{\mathrm{o}}$ Cuerpo de Ejército (Andersen, 2002: 271-272). Y, finalmente, para el caso de Córdoba, contamos con el trabajo
} 
Todo ello no implica negar o relativizar la coordinación operativa entre las FFAA, la policía y el resto de las fuerzas de seguridad, sino que apunta a subrayar que en el ejercicio del plan represivo intervinieron agencias y fuerzas que no siempre colaboraron, sino que tuvieron disputas o fricciones, confrontaron y entraron en tensión, poniendo en cuestión perspectivas que han enfatizado la coordinación "desde arriba" o la existencia de un proceso de militarización sin matices o fisuras.

Finalmente, y en relación con uno de los atributos más señalados sobre el proceso de militarización (v.g. la participación de la policía en la persecución y represión del "enemigo político" y no exclusivamente del delito común), hay un elemento que resulta importante notar: la función principal de la policía era el mantenimiento del orden y la seguridad interna y, por ende, el control, la vigilancia y eventualmente la represión de los sujetos "peligrosos". En tal sentido, esto no configuraría una novedad que se hizo presente en los años 60-70 de la mano del proceso de militarización o de la adopción de estrategias represivas diseñadas por los militares, sino que remite a una larga historia de persecución político-ideológica realizada por la policía.

Las prácticas policiales de represión política y político-social a lo largo del siglo XX (Bohoslavsky, Caimari y Schettini, 2009; Marengo, 2015; Albornoz y Galeano, 2017) muestran una notable continuidad que no podría eludirse a la hora de analizar su involucramiento en la "lucha antisubversiva". E invitan a indagar sobre la rutina de ciertos procedimientos policiales, sobre la articulación operativa con las FFAA y sobre la novedad de la incorporación de prácticas represivas en aquel contexto.

2) En relación con ello, la segunda cuestión que me interesa plantear refiere a la articulación entre "rutina y novedad" en el ejercicio de la represión, constatando que durante casi todo el período bajo análisis la policía cumplió un rol central en la persecución y represión de la conflictividad social y política, que contrasta con la intervención esporádica de las FFAA en el ejercicio represivo y en el mantenimiento del orden interno. ${ }^{16}$

Sin perder de vista la escalada represiva sin precedentes implementada por los distintos gobiernos que se sucedieron entre los años 60 y 80 (Franco, 2012; D’Antonio, 2010), la intervención directa de las FFAA en el ejercicio de la represión se verificó en ciertos contextos y sin continuidad, al menos hasta octubre de 1975 y durante la última dictadura, cuando asumieron completamente el comando de la "lucha antisubversiva".

de Miguel Robles, un ex policía e investigador, que reconstruye el asesinato de policías por parte de miembros del grupo operativo del D-2 (Robles, 2010; Galeano 2013). Para el caso cordobés ver también las declaraciones más recientes del ex capitán Héctor Vergéz, comandante del CCD La Ribera, a un medio periodístico en: http://www.infobaires24.com.ar/los-cuerpos-los-desaparecidos-fueron-trituradosuna-maquina-moler-piedras/

${ }^{16}$ Probablemente por ello, sabemos mucho más de la labor de las policías provinciales en la "lucha antisubversiva" para el período previo al golpe de Estado, que lo que se conoce sobre su actuación en el período en el que se encuentra bajo control operativo de las FFAA (cfr. Rodríguez Agüero, (2010); Gentile, (2010); Scatizza, (2017); Paiaro, (2010 y 2015); Solís y Ponza, (2016). 
Águila. Policías, represión y "lucha antisubversiva": exploraciones sobre el rol de las policías en el accionar...

Ahora bien, está ampliamente demostrado que los cambios ideológicos y doctrinarios gestados desde los años 50 y 60 generaron las condiciones para un involucramiento cada vez más activo de los militares en el aniquilamiento del "enemigo interno" (Pontoriero, 2016) y que el diseño y ejecución de tal estrategia represiva no puede desvincularse de la creciente conflictividad social y política que se extendió entre fines de los 60 y el golpe de 1976. Es muy factible suponer, aunque todavía no poseemos un caudal de estudios similar que el existente para el Ejército, que lo mismo sucedió con el resto de las FFAA y de seguridad, incluyendo las policías.

En ese contexto crecientemente represivo, las policías adecuaron su estructura y funcionamiento a perseguir a la "subversión", utilizando métodos ya probados en la lucha contra la delincuencia común y/o incorporando prácticas y dispositivos represivos más o menos novedosos, lo que se amplificó cuando las FFAA asumieron el comando de la "lucha antisubversiva" y pusieron bajo su control operativo a la policía y las fuerzas de seguridad.

La directiva secreta $\mathrm{n}^{\circ} 404$ de octubre de 1975, una de las normas que estableció las bases operativas de la "lucha antisubversiva" y el control operativo del Ejército sobre las policías, planteaba lo siguiente respecto de las fuerzas provinciales:

"El empleo de los medios policiales provinciales bajo control operacional de una autoridad militar para la lucha contra la subversión se regirá por los criterios siguientes: (1) La autoridad militar con el asesoramiento policial formulará los requerimientos de medios necesarios para la ejecución de cada operación, los que deberán ser satisfechos con carácter prioritario por la autoridad policial pertinente. (2) En los requerimientos operacionales a efectuar a las autoridades policiales se tendrá en cuenta no afectar significativamente su capacidad para el cumplimiento de sus misiones normales. (3) Los medios policiales afectados a una operación permanecerán bajo control directo de la autoridad militar durante el tiempo que demande el cumplimiento de la misión, a cuyo término se reintegrarán a su autoridad natural. (4) Los medios policiales durante el desarrollo de sus misiones específicas ejecutarán aquellas acciones contra la subversión que según la situación local determine la autoridad militar pertinente. (5) En caso de que durante la ejecución de una misión policial específica se detecte un hecho o actividad subversiva, los elementos policiales ejecutarán por propia iniciativa las acciones para su eliminación, informando de inmediato al comando operacional del cual dependen. (6) En el caso de que durante la ejecución de una misión policial específica se detecte un foco subversivo que supere la capacidad de los efectivos o medios policiales, la autoridad militar jurisdiccional prestará apoyo con efectivos 
y medios militares y/o de seguridad con carácter prioritario. (7) En todos los niveles militares de comando, representantes de los elementos policiales provinciales bajo su control operacional integrarán con carácter permanente los organismos de inteligencia y de operaciones". ${ }^{17}$

Es decir que, con todo y las continuidades ya esbozadas, el despliegue de esa específica estrategia represiva -la "lucha antisubversiva"- se sobreimprimió a la actividad habitual de las policías (las misiones normales). Sin dejar de lado la preeminencia del combate contra la delincuencia común, la "lucha antisubversiva" sumó un conjunto de prácticas y acciones a la labor policial, cuyo objetivo era el control, vigilancia y eliminación de una nueva delincuencia, la "subversiva".

Analicemos ahora el caso de la policía de Rosario. En el descargo del ex coronel Carlos A. Ramírez, jefe de la policía provincial entre 1976 y 1979, y enviado al juez federal en 2004, planteaba que "en la estructura de la Policía, todo lo referente a Inteligencia y Lucha Antisubversiva pasaba a depender del II Cuerpo de Ejército, y del Jefe de la Subzona 1 y 2 exclusivamente" y que en la policía provincial, estas tareas quedaron a cargo del comandante Agustín Feced, "seleccionado y designado por el Comando del Cuerpo de Ejército II asumiendo la función de jefe de la Unidad Regional Rosario" con el objetivo de "erradicar la subversión y las causas que favorezcan su existencia".

Según las declaraciones de Ramírez, al asumir la Jefatura de la Policía de la Provincia de Santa Fe

“(...) se me ordenó llevar a cabo la tarea típica de la Policía en época de normalidad, esto es la persecución y represión del delito común, como así también, la de mejorar la calidad profesional de los integrantes de la fuerza (...) no tuve yo participación alguna ni en modo alguno con las tareas, acciones o decisiones de la guerra anti-subversiva". ${ }^{18}$

Sin obviar que el escrito citado constituye una presentación judicial, cuyo objetivo fundamental era desvincularse de la imputación sobre violaciones de los derechos humanos que pesaba sobre Ramírez, la declaración muestra una superposición y/o división de funciones en la policía que resulta verosímil y congruente con lo sucedido en nuestra área de estudio. Aunque la participación de los efectivos y la institución policial en la represión fueron amplias y no podría negarse el conocimiento que los jefes tuvieron de la cuestión, el comando de la "lucha antisubversiva" en la ciudad de Rosario quedó en manos de Agustín Feced -jefe de la Unidad Regional II- y el perfil del

\footnotetext{
${ }^{17}$ Directiva del Comandante General del Ejército No 404/75 (Lucha contra la subversión), en Documentos del Estado Terrorista (2012), Cuadernos del Archivo Nacional de la Memoria No 4, Recuperado de: http://www.jus.gob.ar/media/1129178/41-anm-documentos_del estado terrorista.pdf.

${ }^{18}$ Causa Feced, cuerpo 53, fs. 11068/070.
} 
Águila. Policías, represión y "lucha antisubversiva": exploraciones sobre el rol de las policías en el accionar...

comandante es un componente significativo de las modalidades que asumió el ejercicio represivo en ese ámbito local.

El ímpetu y la saña con las que Feced implementó la persecución del “enemigo subversivo" en el ámbito urbano, antes y después de 1976, deben ser enfatizados. Feced ${ }^{19}$ había sido Jefe de la Policía local entre 1970 y 1972, en el contexto crecientemente represivo abierto desde 1969 por los Rosariazos y el Cordobazo, y su jefatura coincidió con la llegada a la comandancia del $\mathrm{II}^{\mathrm{o}}$ Cuerpo del General Juan Carlos Sánchez, uno de los "duros" del elenco militar. En esos años la policía rosarina llevó adelante una intensa actividad "antisubversiva", que para 1971 se subordinó a las directivas militares de acuerdo con la Ley $N^{o}$ 19.801/71, que estableció el control operacional del Comando de cuerpo respectivo sobre las fuerzas policiales. A poco de aprobarse dicha ley -que facultaba la intervención de las FFAA para "prevenir y combatir a la subversión"-, se produjo un visible aumento de la participación del Ejército en las acciones represivas y un recrudecimiento de la "lucha antisubversiva" a escala local y provincial. ${ }^{20}$

Esta actividad no sólo incluyó prácticas habituales de la policía, que se inscribían en la normativa vigente y tenían por objetivo el "mantenimiento del orden público y la paz social" a través de métodos en general brutales -la represión de manifestaciones en el espacio público, la realización de allanamientos y detenciones para detectar "células subversivas"-, sino también otras que tuvieron un carácter extralegal o paralegal.

La ley orgánica de la policía de Santa Fe (aprobada por decreto en 1972 y promulgada como ley provincial en 1975), que modificó la estructura orgánica con la creación de distintas unidades regionales que abarcan uno o más departamentos provinciales y funcionan bajo la dirección de la Jefatura de Policía con asiento en la ciudad de Santa Fe (Barrera, 2015: 66), estipulaba que la policía provincial debía, entre otras funciones:

"Prevenir y reprimir toda perturbación del orden público, garantizando especialmente la tranquilidad de la población y la seguridad de las personas y la propiedad contra todo ataque o amenaza (...); Asegurar la plena vigencia de los poderes de la Nación y la Provincia, el orden constitucional y el libre ejercicio de las instituciones políticas, previniendo $\mathrm{y}$ reprimiendo todo atentado o movimiento subversivo (...);

\footnotetext{
${ }^{19}$ Feced no era militar, sino comandante retirado de Gendarmería. Aunque es necesario hacer constar que según la ley vigente en el período, Gendarmería Nacional era "una fuerza de seguridad militarizada, dependiente del Comando en Jefe del Ejército, estructurada para cumplir las misiones que precisa esta ley, en la zona de Seguridad de Fronteras y demás lugares que se determinen al efecto". Ley No 19.349, Recuperado de: http://infoleg.mecon.gov.ar/infolegInternet/anexos/35000-39999/38871/texact.htm.

${ }^{20}$ Un ejemplo de ello fue la creación, en mayo de 1971, de la Central de Inteligencia de la Provincia (CIP) por el gobierno del General Guillermo Sánchez Almeyra, considerando que "la necesidad de la labor de Inteligencia a nivel provincial resulta de primordial importancia y urgencia". La CIP coordinaría las actividades de inteligencia a escala provincial, subordinando al organismo precedente, la Dirección General de Informaciones de la Provincia. La prioridad otorgada por el gobierno provincial a las tareas de inteligencia debe ser entendida en aquel contexto de reforzamiento de la actividad represiva (Águila, 2013b).
} 
Desarrollar toda actividad de observación y vigilancia destinada a prevenir el delito y aplicar para tal fin los medios; Intervenir en la realización de las reuniones públicas para mantener el orden y prevenir y reprimir el delito, incidentes, disturbios y manifestaciones prohibidas; Velar por las buenas costumbres en cuanto puedan ser afectadas por actos de escándalo público $(\ldots)^{\prime \prime} \cdot{ }^{21}$

Este marco legal, que facultaba a la policía a participar de la "lucha antisubversiva", se completó con la participación de algunos de sus efectivos en organismos "antisubversivos", que tuvieron intervención en secuestros y desapariciones de militantes políticos en particular durante el año 1972 y que preanunciaban lo que sucedería en los años de la última dictadura (Águila et al., 2017).

Cuando Feced regresó a la jefatura de la policía local, pocos días después del golpe de Estado de 1976, la institución se convirtió en uno de los vectores más eficaces de la "lucha antisubversiva", que se amplificó y profundizó. En su escueto discurso de toma de posesión quedó plasmado el perfil de quien dirigiría uno de los principales circuitos represivos de la provincia:

"Seré muy breve señores. Estamos al pie de continuar con una batalla inconclusa contra la insurrección apátrida (...) parece que va a ser el momento de pelear. Con esto queda notificada la insurrección. No los estaremos esperando sino que los atacaremos ya (...) comenzaremos la guerra total contra la guerrilla y la subversión. A los extremistas les digo que a partir de este momento tienen doce horas para abandonar la ciudad. De lo contrario nosotros los acompañaremos al cementerio". ${ }^{22}$

A partir de su asunción, la policía local puso en marcha una vasta "lucha antisubversiva" que conjugó distintos frentes: participó activamente de acciones represivas "legales", que incluyeron operativos y procedimientos "antisubversivos" en el ámbito urbano en conjunto con el Ejército y otras fuerzas (Gendarmería, Policía Federal) y la persecución de la delincuencia común, hasta una campaña -de alcances sociales más vastos- de "moralización de lugares nocturnos y de saneamiento de las costumbres" (Águila, 2008). ${ }^{23}$

\footnotetext{
${ }^{21}$ Ley N $7395 / 75$, Ley Orgánica de la Policía de la Provincia de Santa Fe, art. 9, Recuperado de: https://www. santafe.gov.ar/index.php/web/content/download/214420/1111271/file/Ley\%20org\%C3\%A1 nica\%20 de\%201a\%20polic\%C3\%ADa\%20de\%20Santa\%20Fe\%20N\%C2\%B0\%207395.pdf.

${ }^{22}$ Diario La Capital, 10/4/76.

${ }^{23}$ De hecho, uno de los logros más entusiastamente señalados por la prensa local, los funcionarios municipales y las "fuerzas vivas" de la ciudad en los tramos iniciales de la dictadura fue la disminución del delito común y los éxitos de la campaña moralizadora llevada adelante por la policía provincial los que -como sostenía el principal diario de la ciudad- habían contribuido a reinstalar el orden en el ámbito urbano. En su informe de octubre de 1976, el jefe de policía provincial, coronel Carlos A. Ramírez, daba cuenta de una disminución del $4,91 \%$ del número de delitos en el semestre posterior al golpe de estado (18.230 delitos) en relación con el último de 1975 (20.110 delitos). Diario La Capital, 6/10/76.
} 
Águila. Policías, represión y "lucha antisubversiva": exploraciones sobre el rol de las policías en el accionar...

Por su parte, y en lo que refiere a la dimensión clandestina o extralegal de la represión, la participación de la policía en la realización de operativos "antisubversivos" (en forma autónoma o en procedimientos conjuntos, antes y mientras estuvieron bajo el "control operacional" de las Fuerzas Armadas) o la utilización de las comisarías y jefaturas de policía como lugares de detención, se articuló con la rápida constitución de un eficiente grupo de tareas que actuaba en el área de Rosario, cuya base estaba en las dependencias de la Jefatura de Policía (Águila, 2016). Como veremos, la información de inteligencia colectada por el Servicio de Informaciones (D-2) y el conocimiento del territorio que la policía tenía le otorgaron a la institución un papel significativo en el desarrollo de la "lucha antisubversiva".

Un elemento más a considerar aquí tiene que ver con ciertos procedimientos propios de la policía y que eran moneda corriente bastante antes del período bajo estudio: el ejercicio de la brutalidad sobre los detenidos y la comisión de delitos comunes. Como sabemos, ambos elementos fueron también constitutivos de la represión en los años 70 , en distintas jurisdicciones e indistintamente en el caso de militares y policías. En este punto, lo cierto es que no supusieron una ruptura con procedimientos "rutinarios" y ampliamente instalados en el accionar policial si bien queda por ver en qué medida la "lucha antisubversiva" propició, generalizó o acentuó estos comportamientos en las filas policiales (Del Frade, 2004; Robles, 2010).

3) La tercera cuestión que me interesa analizar es el modo en el que la policía se implicó en la "lucha antisubversiva". Si por un lado está ampliamente probado el amplio involucramiento de las policías en el accionar represivo, por otra parte, hay un ámbito que parece ostentar un rol central: los D-2, los departamentos o servicios de informaciones de la policía. ${ }^{24}$ Examinaré la cuestión en mi caso de estudio.

En la esfera del Servicio de Informaciones de la policía rosarina, se estructuró uno de los circuitos represivos más importantes del sur de la provincia de Santa Fe. Con un nivel de autonomía bastante amplio, entre 1976 y principios de 1978, el grupo operativo al mando de Feced llevó adelante cientos de detenciones y secuestros, derivando a los prisioneros hacia las dependencias del Servicio de Informaciones, donde permanecieron en calidad de detenidos-desaparecidos durante un tiempo variable y fueron sometidos a sesiones de tortura con el objetivo de reunir información. Aunque en una proporción muy elevada los detenidos en ese lugar fueron liberados y sobrevivieron, varios cientos fueron asesinados o permanecen desaparecidos. Así, por su centralidad en el esquema represivo y el elevado número de víctimas, el Servicio de Informaciones de la policía fue,

\footnotetext{
${ }^{24}$ Uno de los pocos trabajos académicos que han analizado el funcionamiento de los D-2 es el de Margaria y Schnyder (2017), centrado en el estudio aquel organismo de la policía de la provincia de Santiago del Estero entre los años 1950 y los 2000. Allí hacen constar que "el informe Nunca Más elaborado por la CONADEP identificó como centros clandestinos de detención los D-2 de las policías de Córdoba, Mendoza, Misiones, San Juan, Jujuy y Santiago del Estero. En la actualidad está siendo investigada la participación del D-2 en actividades represivas durante la dictadura en el marco de los juicios contra los represores que se están desarrollando en las provincias de Mendoza, Córdoba, San Luis, La Pampa, Tucumán y Santiago del Estero". Para las otras provincias, las menciones sobre el funcionamiento de los D-2 se encuentran fundamentalmente en informes de organismos de derechos humanos y la justicia.
} 
en el contexto de mayor represión, el centro clandestino de detención más importante del sur de la provincia de Santa Fe.

El Servicio de Informaciones era una dependencia orgánica de la Unidad Regional II de Policía y funcionaba en el edificio de la Jefatura de Policía de Rosario, en pleno centro de la ciudad. ${ }^{25}$ Con distintos nombres según la época (División de Informaciones, Departamento de Informaciones o D-2, Servicio de Informaciones), tenía como misión principal "reunir, procesar y difundir toda información que permita conocer la real situación de las organizaciones delictivas que operan en el ámbito de su provincia", vinculado con "delitos comunes, actividades extremistas y todo lo que haga a los asuntos políticos, gremiales, estudiantiles, migratorios, turísticos, económicos, etcétera, que tengan incidencia en el ámbito provincial". Asimismo, entre sus misiones $\mathrm{y}$ funciones estaba cooperar con otros departamentos de informaciones policiales y organismos de inteligencia. ${ }^{26}$

Esta función, la de reunir y procesar información para tareas de inteligencia, colocó al Servicio de Informaciones de la policía de Rosario en un lugar clave para el desarrollo de la "lucha antisubversiva" mientras duró la comandancia de Feced, considerando la centralidad que tenía la obtención de información para la detección del "enemigo interno", la desarticulación de redes militantes, el aniquilamiento de las organizaciones "subversivas". 27

Por su parte, junto con albergar una de las principales agencias de inteligencia que actuaban en el área de Rosario, ${ }^{28}$ la Jefatura de Policía era desde mediados de los años 70 el principal centro de radicación de prisioneros del sur de la provincia, cuyo número se incrementó notablemente al compás del incremento del accionar represivo. ${ }^{29}$

${ }^{25}$ Las dependencias del Servicio de Informaciones estaban localizadas en la Jefatura de Policía, si bien entre 1971-73 el organismo funcionó en la Comisaría 2a donde, y según declaraciones de Lofiego, "actuaba un grupo antisubversivo denominado Belén Blanco, integrado por personal de la policía provincial, federal, y quizás de otras fuerzas..." (Causa Feced, cuerpo 51, fs. 10570). Por su parte, algunos de los miembros del SI fueron sindicados, e incluso procesados por la desaparición o el asesinato de militantes políticos entre 1972 y 1975, mostrando el involucramiento del organismo en la represión paraestatal en el período previo al golpe de 1976. Cfr. las declaraciones de Lofiego en Causa Feced, cuerpo 49, fs. 10301.

26 "Reglamento del Departamento de Informaciones Policiales", en Tschopp, 2001: 285-296.

${ }^{27}$ En el testimonio de Gustavo Bueno, uno de los miembros del Destacamento de Inteligencia Militar 121, éste sostuvo que a partir de 1976 las operaciones fueron llevadas adelante por la policía "porque tenía la información que habían venido acumulando (...) llevaban a cabo investigaciones pero eran gente directamente del Servicio de Informaciones; entonces ahí, cuando estaba el comandante mayor retirado de Gendarmería Nacional, Agustín Feced; es quien, es decir, comanda operaciones ya directamente". Testimonio de Gustavo Bueno ante el CELS, 1984, mimeo.

${ }^{28} \mathrm{He}$ analizado la fluida circulación de información entre las diversas agencias de inteligencia en la denominada "comunidad informativa", que se constituyó en los meses previos al golpe y estaba integrada en el área de Rosario (COMINSARIO) por el Servicio de Informaciones de la URII, el Departamento Inteligencia Militar 121, la delegación local de la Secretaría de Inteligencia del Estado (representada por la Dirección General de Informaciones de la Provincia), y organismos dependientes de la Policía Federal, de Gendarmería y de Prefectura Naval. Cfr. Águila, 2013b.

${ }^{29}$ En un informe elevado a la justicia hacia fines de 1986, la División de Informaciones de la Unidad Regional II de Policía explicaba que: "Los distintos procedimientos y/o detenciones, se efectivizaban bajo Control Operacional del Comando de Cuerpo de Ejército II, Tte. Gral. Juan Carlos Sánchez, por imperio del Estado de Sitio y relacionados con irregularidades en que incurrían los activantes, como resultado de las transgresiones a las Leyes Nacionales y normas legales vigentes en cada caso, que 
Águila. Policías, represión y "lucha antisubversiva": exploraciones sobre el rol de las policías en el accionar...

Finalmente, a ello hay que agregarle el rol que la policía venía cumpliendo, bastante antes del golpe de Estado, en la represión de la conflictividad social y en la persecución de la delincuencia "subversiva" en el contexto local y provincial.

El grupo operativo (la "patota", el "grupo de tareas") que actuaba en el Servicio de Informaciones de la Jefatura de Policía de Rosario se conformó en 1976. Varios de sus integrantes venían cumpliendo funciones en esta dependencia desde antes del golpe de Estado, tanto los que se desempeñaron como jefes y subjefes del servicio (los comisarios Juan José Seichuk, Raúl Guzmán Alfaro y Roberto Scardino) y algunos oficiales y suboficiales que se desempeñaban en sus distintas secciones (entre ellos José Lofiego). ${ }^{30}$

Por sus legajos y las declaraciones de algunos de sus miembros, sabemos que otros integrantes fueron traslados al Servicio hacia 1976 ó 1977, requeridos por los jefes o algunos oficiales influyentes, provenientes de distintas reparticiones: el Comando Radioeléctrico, ${ }^{31}$ Seguridad Personal, Robos y Hurtos, el Cuerpo de Infantería o la Brigada de Explosivos. ${ }^{32}$

El Servicio de Informaciones tenía distintas divisiones y secciones: Reunión, Investigación de Informaciones, Planes e Instrucción, Sección Central, divididos a su vez en secciones. Ello implicaba tareas y funciones diferenciadas, no sólo entre el personal jerárquico y sus subordinados, sino también entre los que se encargaban de las distintas tareas en el ámbito policial: recolección de información por distintos canales, "explotación” de los medios de prensa, elaboración de informes, logística, participación en los operativos callejeros o tomar declaraciones y "hacer las fichas" de los detenidos. Asimismo y cuando el Servicio de Informaciones se pobló de detenidos, además de los encargados del "papeleo" y las tareas administrativas o de la logística, se sumaron efectivos de la guardia de prevención para la custodia de los prisioneros.

Parece cierto que todos ellos formaron parte en distintos momentos del grupo operativo, que participaron de allanamientos y acciones en la calle y desempeñaron de

penaban el accionar terrorista, destacándose que esta UR II - Policía de Rosario, funcionaba como lugar de recepción de todos los detenidos de la zona sur de la Provincia, ya sea como resultado de procedimientos efectuados por personal militar y/o policial" (Causa Feced, c. 32, fs. 6462, el subrayado es mío).

${ }^{30}$ Lofiego era uno de los principales oficiales del Servicio de Informaciones, sindicado por los detenidos como el principal torturador y, en las actuaciones judiciales posteriores, uno de los imputados que más ampliamente brindó declaración. Al respecto las declaraciones de José Lofiego en Causa Feced, cuerpo 49, fs. $10301 / 302$.

${ }^{31}$ Señalemos que frecuentemente los móviles del Comando Radioléctrico participaban en los operativos y detenciones llevadas adelante junto con los miembros del Servicio de Informaciones y el propio Feced. Cfr. el trabajo de Paiaro (2015) sobre el Comando Radioeléctrico en Córdoba.

32 También por sus legajos sabemos que muchos de ellos eran hombres jóvenes al momento del golpe de estado. Si bien los jefes (Feced, Guzmán Alfaro, Seichuk) pasaban los 40 ó 50 años, una parte importante del grupo operativo tenía entre 20 y poco más de 30 años. Y como en general sucedía en los efectivos de la policía provincial, el nivel de instrucción era primario o bien secundario incompleto. Quienes tenían educación universitaria eran raras avis, como Lofiego, que había estudiado 5 años de la carrera de Medicina. Finalmente, ninguno de los involucrados en el Servicio de Informaciones parece haber tenido formación específica en Inteligencia, como es usual encontrar en el caso de los militares que integraron grupos operativos. En sus legajos no consta la realización de cursos o entrenamiento en tales tareas, e incluso varios de ellos declararon explícitamente no haber tenido formación en el área. Los legajos personales de todos los indagados en la Causa Feced hasta el año 1987 se encuentran en el cuerpo 37. 
distintas tareas en el marco de la "lucha antisubversiva". Lofiego declaraba que, debido al escaso número de efectivos con que contaba esa dependencia (unas 15 personas), el trabajo era rotativo y debían cubrir el servicio permanentemente. ${ }^{33} \mathrm{Y}$ agregaba que "el Servicio de Informaciones no era una fuerza exclusiva para luchar contra la subversión pues cualquier numerario de la fuerza policial podía ser exigido para ello" ${ }^{34}$

Este mecanismo que determinaba los que allí revistaban -y que se extendió a otras dependencias policiales- fueran requeridos para intervenir en procedimientos y cumplir diversas funciones como realizar interrogatorios y ocuparse de los detenidos (si bien no todos realizaban cada una de ellas) es una demostración del involucramiento que tuvo gran parte de la fuerza policial en el accionar represivo a nivel local, tanto como la innegable centralidad del Servicio de Informaciones en la realización de operaciones "antisubversivas".

4) La última cuestión que quiero explorar brevemente es el problema de la territorialidad de la represión. Es un hecho ampliamente conocido que en el curso del año 1975 se estableció el plan de operaciones para la "aniquilación de la subversión", sobre la base de un esquema de división del territorio nacional en zonas, subzonas y áreas, que constituyeron espacios jurisdiccionales donde operarían militarmente, bajo un único mando, las fuerzas represivas. Así, y en términos operativos, la represión se implementó a escala territorial, definiendo los límites de los circuitos represivos, los recursos utilizados y las fuerzas actuantes.

El "control operativo" de las FFAA y en particular del Ejército sobre las otras fuerzas represivas y de seguridad que actuaban en las distintas zonas, subzonas y áreas supuso una superposición de jurisdicciones entre agencias represivas que actuaban en el mismo territorio. Y mientras en algunos casos las fuerzas represivas actuantes se subordinaron rápidamente al comando militar en la "lucha antisubversiva", en otros - como sucedió con la URII dirigida por Feced- la policía no cedió inmediatamente la responsabilidad operacional.

Así, y tal como se verificó en nuestro caso de análisis, la asunción por parte de las FFAA de la dirección de la represión del conflicto interno - esto es, de misiones y funciones que venían siendo cumplidas por las fuerzas policiales- convivió con tensiones y disputas más o menos veladas con la policía local que pusieron en acto uno de los atributos centrales de la policía: el conocimiento del territorio (Rosignoli, 2014; Barrera, 2014).

A diferencia del Ejército, ${ }^{35}$ el hábitat natural de la policía estaba en la calle; la policía conocía el territorio, tanto como a quienes militaban y sus ámbitos de actuación.

\footnotetext{
${ }^{33}$ Y agrega "no como en Robos y Hurtos o Moralidad Pública donde había más gente y las tareas se encontraban repartidas". Causa Feced, cuerpo 12, fs. 276.

${ }^{34}$ Causa Feced, cuerpo 49, f. 10302. El subrayado es mío.

${ }^{35}$ Ello no elude que el Ejército diseñó e implementó estrategias dirigidas al control del territorio o de la población, como lo muestran los estudios sobre acción cívica realizados por Divinzenso (2017) o los trabajos sobre Tucumán y el Operativo Independencia (Garaño, 2012; Nemec, 2017).
} 
Águila. Policías, represión y "lucha antisubversiva": exploraciones sobre el rol de las policías en el accionar...

En una estrategia represiva donde la territorialidad era central, ese conocimiento le otorgó a la policía un rol clave en el despliegue de la represión en nuestra área.

Este control del territorio por parte de la policía se verificó en particular durante los primeros años de la dictadura, tanto en la producción de información de inteligencia (tal como hemos descripto para el Servicio de Informaciones) como en la realización de la mayor parte de las prácticas represivas legales y clandestinas, sin dejar de señalar la recurrencia de los operativos conjuntos entre las fuerzas represivas y la creciente intervención del Ejército.

Si a partir del golpe de Estado y durante 1976 y gran parte del año 1977 la policía comandada por Feced y el grupo operativo del Servicio de Informaciones tuvieron una participación central en el ejercicio de la represión en Rosario, imponiéndole un sello propio al mismo, para mediados de 1977 la presencia del Ejército se incrementó no sólo en la realización de procedimientos, sino también en la actividad clandestina -medido en el rol que cumplió el Destacamento de Inteligencia 121, sede del otro circuito represivo que operó en Rosario (Águila, 2017)-, restándole autonomía operativa a la policía local (aunque el centro de detención clandestina localizado en el Servicio de Informaciones siguió funcionando durante todo el año 1978). ${ }^{36}$

\section{A modo de cierre provisorio}

Este trabajo ha pretendido aportar en un área de (relativa) vacancia en el campo de estudios sobre la policía y en la línea de indagación sobre la represión y la violencia estatal y paraestatal en la historia reciente argentina, a través de la exploración de la actuación de las policías en el contexto de mayor intensidad represiva, proponiendo algunas claves de análisis y poniendo el foco en un caso específico: el de una policía provincial y su actuación en un centro urbano principal, por lo demás uno de los principales escenarios de la represión a nivel nacional.

Las entradas analíticas que presenté incluyeron, en primer lugar, poner en debate los alcances y atributos de una categoría muy utilizada para referir a la actuación de la policía, cual es la de militarización, alertando sobre su uso acrítico. Por otro lado, me interesó plantear la articulación entre la rutina de ciertos procedimientos policiales y la novedad de la incorporación de prácticas represivas en el contexto la "lucha antisubversiva", lo que permitiría discutir continuidades y rupturas así como las temporalidades en el ejercicio de la represión. En tercer lugar, me ocupé de explicar las modalidades de involucramiento de la policía en dicho accionar tanto como la centralidad del D-2 en la "lucha antisubversiva" y, finalmente, esbocé el problema de la territorialidad para pensar la relación entre autonomía y coordinación operativa de las fuerzas represivas, considerando la escala de análisis. Todas ellas resultan pertinentes

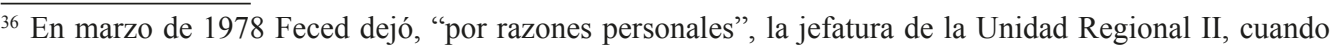
el accionar represivo en el área ya había perdido la virulencia de los años anteriores. El escritor Miguel Bonasso hace constar, citando testimonios de presas políticas en la cárcel de Villa Devoto, que el alejamiento de Feced habría tenido que ver con los cuestionamientos que despertaba en los medios militares sus métodos brutales y criminales. Su alejamiento habría dejado la represión en manos de los mandos militares (Bonasso, 2003: 143).
} 
y permiten complejizar el abordaje de las policías, pero es claro que no son las únicas posibles.

Para finalizar quisiera señalar que, como todo estudio de caso, esta aproximación conlleva como riesgo la tentación de generalizar los atributos específicos que exhibió la policía rosarina en el período (en particular el grado de autonomía que la caracterizó en los primeros años de la dictadura), pero a la vez tiene la ventaja de ser un caso que permite mostrar un panorama más complejo y diverso del accionar represivo, que pone en tensión las explicaciones más difundidas sobre la subordinación de las policías a las FFAA y que, finalmente, contribuye a problematizar las modalidades y dinámicas de acción de dichas agencias estatales en el contexto de mayor intensidad represiva.

\section{Referencias bibliográficas}

Abregú, M., Palmieri, G. \& Tiscornia, S. (1998). "Informe sobre la situación y los mecanismos de control de los organismos de seguridad pública interior en la República Argentina". En H. Frühling (ed.) Control Democrático en el Mantenimiento de la Seguridad Interior. Santiago de Chile: Centro de Estudios del Desarrollo.

Águila, G. (2013b). “La represión en la Argentina: modalidades, dinámicas regionales y efectos sociales". En G. Águila \& L. Alonso (comps.) Procesos represivos y actitudes sociales: entre la España franquista y las dictaduras del Cono Sur (pp. 97-121). Buenos Aires: Prometeo. [Recuperado de: http://historiapolitica.com/ datos/biblioteca/represionestatal_aguila.pdf]

Águila, G. (2013b.) "Las tramas represivas: continuidades y discontinuidades en un estudio de caso. La Dirección General de Informaciones de la Provincia de Santa Fe, 1966-1991". Sociohistórica, 31. [Recuperado de: http://www.sociohistorica. fahce.unlp.edu.ar/article/view/SHn31a01/pdf.]

Águila, G. (2017). "Represión y terror de estado en la historia reciente argentina: nuevos abordajes y perspectivas de análisis". Ayer. Revista de Historia Contemporánea, 107, 47-71.

Águila, G. (dir.) et al. (2017). Territorio ocupado. La historia del Comando del II Cuerpo de Ejército en Rosario (1960-1990). Rosario: Editorial Municipal de Rosario/Museo de la Memoria.

Águila, G., Garaño, S. \& Scatizza, P. (coords.). (2016). Represión estatal y violencia paraestatal en la historia reciente argentina: nuevos abordajes a 40 años del golpe de Estado. La Plata: Ediciones FaHCE, Universidad Nacional de La Plata. [Recuperado de: http://www.libros.fahce.unlp.edu.ar/index.php/libros/catalog/ book/63.]

Andersen, M. E. (2002). La Policía. Pasado, presente y propuestas para el futuro. Buenos Aires: Sudamericana.

Bailey, J. (2010). “¿Militarización policial?”, en El Universal, 16/1/10. [Recuperado de: www.mexiconews.com.mx/editoriales/36523.html.] 
Águila. Policías, represión y "lucha antisubversiva": exploraciones sobre el rol de las policías en el accionar...

Barragán, I. \& Iturralde, M. (2017). "La Fuerza de Tareas 6 de la Armada Argentina. Apuntes y consideraciones sobre la gestión de detenidos-desaparecidos a partir de la Mega-causa "Base Naval Mar del Plata"'. $1^{\circ}$ Workshop "Tramas represivas, violaciones a los derechos humanos y tramitación del pasado a escala local. Las ciudades de Mar del Plata y Bahía Blanca durante la última dictadura militar", Mar del Plata.

Barragán, I. \& Zapata, A. B. (2015). "Dictadura militar y represión a la clase trabajadora. La Armada Argentina, marco doctrinario y operaciones represivas en perspectiva regional para los casos de Ensenada y Bahía Blanca", Diacronie, 24, 4. [Recuperado de: http://www.studistorici.com/2015/12/29/barragan-zapata numero_24/]

Barreneche, O. (2010). "De brava a dura. La policía de la provincia de Buenos Aires durante la primera mitad del siglo XX". Cuadernos de Antropología Social, 32, 31-56.

Barreneche, O. \& Galeano, D. (2008). "Notas sobre las reformas policiales en Argentina". Cuadernos de Seguridad, 73-114.

Barreneche, O. (2007). "La reforma policial del peronismo en Provincia de Buenos Aires, 1946-1951". Desarrollo Económico, 47(186), 225-248.

Barreneche, O. (2008). "La reorganización de las policías de Córdoba y Buenos Aires, 1935-1940”. En B. Moreyra \& S. Mallo (coords.). Pensar y construir los grupos sociales. Actores, prácticas y representaciones: Córdoba y Buenos Aires, siglos XVI-XX (417-436). Córdoba: Centro de Estudios Históricos "Prof. Carlos Segreti" y UNC.

Barreneche, O. (2010). "Manejo metodológico de las fuentes documentales y los archivos policiales. El caso de la Policía de la Provincia de Buenos Aires". Revista Electrónica de Fuentes y Archivos del Centro de Estudios Históricos "Prof. Carlos S. A. Segreti", 1. [Recuperado de: http://www.refa.org.ar/contenidoautores-revista.php?idAutor $=13$.]

Barreneche, O. (2011). "Paro de y represión a... policías. Reclamos salariales, protestas y huelga en la policía bonaerense (1955-1973)", en Desarrollo Económico. Revista de Ciencias Sociales, 51(202-203), 53-88.

Barreneche, O. (2012). "Formas de violencia policial en la provincia de Buenos Aires a comienzos de la década de 1960", en Anuario del Instituto de Historia Argentina, 1(12). [Recuperado de: http://www.anuarioiha.fahce.unlp.edu.ar/article/view/ IHAn12d08]

Barrera, N. (2014). "Policía, territorio y discrecionalidad: una etnografía sobre la espacialidad en las prácticas policiales en la ciudad de Rosario". En S. Frederic, M. Galvani, J. Garriga Zucal \& B. Renoldi (eds.) De armas llevar: El Estado y las fuerzas de seguridad: quehaceres, relaciones y cambios (355-377). La Plata: EPC ediciones

Barrera, N. 2015. Usos de la fuerza y ciudadania: una etnografía de las prácticas policiales en la ciudad de Rosario (Tesis de doctorado). [Recuperado de: http:// hdl.handle.net/2133/9173.] 
Barry, V. (2010). “Los pasos para la modernización policial. Reclutamiento e instrucción en la policía de la ciudad de Buenos Aires, 1880-1910”. [Recuperado de: http:// historiapolitica.com/datos/biblioteca/saberes\%20del\%20crimen_barry.pdf.]

Bianciotto, M. L. (2014). "Repensando la homogeneidad policial: a propósito de las prácticas de comisaría y "calle" en la ciudad de Rosario". Publicar, XVII. [Recuperado de: http:/ppct.caicyt.gov.ar/index.php/publicar/article/ viewFile/4666/5549.

Bohoslavsky, E. (2010). "El brazo armado de la improvisación. Apuntes para una historia social de los policías patagónicos (1880-1946)". En E. Bohoslavsky \& G. Soprano (comps.) Un Estado con rostro humano. Funcionarios e instituciones estatales en Argentina (desde 1880 hasta la actualidad) (215-242). Buenos Aires: UNGS/Prometeo.

Bohoslavsky, E. (2010). “Modernización estatal y coerción: el lugar de la policía en el avance del estado argentino en la frontera (1880-1946)". En E. Bohoslavsky, L. Caimari \& C. Schettini (orgs.) La policía en perspectiva histórica.

Bohoslavsky, E., Caimari, L. \& Schettini, C. (orgs.). (2009). La policía en perspectiva histórica. Argentina y Brasil (del siglo XIX a la actualidad) [CD-Rom]. Buenos Aires.

Bonasso, M. (2003). Recuerdo de la muerte. Buenos Aires: Planeta.

Caimari, L. (2004). Apenas un delincuente. Crimen, castigo y cultura en la Argentina, 1880-1955. Buenos Aires: Siglo XXI.

D’Antonio, D. \& Eidelman, A. (2010). "El sistema penitenciario y los presos políticos durante la configuración de una nueva estrategia represiva del Estado argentino (1966-1976)". Iberoamericana, 10(40), 93-111. [Recuperado de: https://journals. iai.spk-berlin.de/index.php/iberoamericana/article/view/676.]

D’Antonio, D. (2016). "Consejos de guerra, legalidad autoritaria y nuevo orden jurídico", en Funes, P. (dir.) Revolución, dictadura y democracia. Lógicas militantes y militares en la historia argentina en el contexto latinoamericano (89-120). Buenos Aires: Imago Mundi.

Dammert, L. (2005). "Reforma policial en América Latina”, en Quórum. Revista de pensamiento iberoamericano, 12, 53-64. [Recuperado de: http://www.redalyc. org/pdf/520/52001205.pdf.]

Del Frade, C. (2004). Matar para robar, luchar para vivir: historia politica de la impunidad, Santa Fe, 1976-2004. [Recuperado de: http:/www.desaparecidos. org/nuncamas/web/investig/frade04/frade04_00.htm.]

Divinzenso, A. (2017). "El Ejército y la sociedad rosarina: La "Acción Cívica” del II Cuerpo (1960-1983)", en Águila, G. (dir.) et al. Territorio ocupado. La historia del Comando del II Cuerpo de Ejército en Rosario (1960-1990) (207-260). Rosario: Editorial Municipal de Rosario/Museo de la Memoria.

Eidelman, A. (20109. El desarrollo de los aparatos represivos del Estado argentino durante la "Revolución Argentina", 1966-1973 (Tesis de Doctorado). [Recuperado de: http://repositorio.filo.uba.ar/handle/filodigital/1412] 
Águila. Policías, represión y "lucha antisubversiva": exploraciones sobre el rol de las policías en el accionar...

Eidelman, A. (2012). “Construcción de la identidad policial y representación de la violencia política en la revista PFA-Mundo Policial durante los años 70”, en Contemporánea. Historia y problemas del siglo $X X, 3(3)$. [Recuperado de: $\quad$ http://www.geipar.udelar.edu.uy/wp-content/uploads/2014/10/ Contemporanea03_2012-11-23-webO-03.pdf.]

Frederic, S. (2008). Los usos de la fuerza pública. Debates sobre militares y policías es las ciencias sociales de la democracia. Buenos Aires: UNGS-Biblioteca Nacional.

Frederic, S., Galvani, M., Garriga Zucal, J. \& Renoldi, B. (eds.) (año?) De armas llevar: El Estado y las fuerzas de seguridad: quehaceres, relaciones y cambios (355377). La Plata: EPC ediciones

Funes, P. (2004). "Medio siglo de represión. El Archivo de la Dirección de Inteligencia de la Policía de la Provincia de Buenos Aires", Puentes, 4(11), 35-43.

Galeano, D. (2007). "En nombre de la seguridad. Lecturas sobre policía y formación estatal", en Cuestiones de sociología. Revista de estudios sociales, 4, 102-125. [Recuperado de: http://www.cuestionessociologia.fahce.unlp.edu.ar/article/view/ CSn04a05.]

Galeano, D. (2013). "Policías que mataron policías: a propósito de La búsqueda. Una entrevista con Charlie Moore (Miguel Robles, 2010)", en Corpus. Archivos de la alteridad americana, 3(2), Recuperado de: http://journals.openedition.org/ corpusarchivos/587.

Galeano, D. \&Albornoz, M. (2017). “Anarquistas y policías en el atlántico sudamericano: una red transnacional, 1890-1910”. Boletín del Instituto de Historia Argentina y Americana "Dr. Emilio Ravignani”, 47, 101-134. [Recuperado de: http://ppct. caicyt.gov.ar/index.php/ravignani/article/view/11080/html

Garaño, S. (2009). "Pabellones de la muerte: los límites difusos entre la represión legal y la clandestina”. Entrepasados, 34, 33-53. [Recuperado de: http://historiapolitica. com/datos/biblioteca/represionestatal_garano.pdf]

Garaño, S. (2010). "El 'tratamiento' penitenciario y su dimensión productiva de identidades entre los presos políticos (1974-1983)". Iberoamericana, 10(40), 113-130. [Recuperado de: http://www.iai.spk-berlin.de/fileadmin/ dokumentenbibliothek/Iberoamericana/40-2010/40_Garano.pdf]

Gayol, S. \& Kessler, G. 2002. Violencias, justicias y delitos en la Argentina. Buenos Aires: Manantial/UNGS.

Gentile, B. (2013). “Anticipando el golpe: policías terroristas en Neuquén y Bahía Blanca". En Servetto, A. (coord.) Dossier "Conflicto, violencia y terror en la Argentina predictatorial. Estudios de casos provinciales". Polhis. Boletín bibliográfico electrónico del Programa Interuniversitario de Historia Política, 12. [Recuperado de: http://historiapolitica.com/datos/boletin/PolHis_12.pdf]

González, G. (2005). "Intentos de reformas policiales en Argentina: los casos de las provincias de Santa Fe y Buenos Aires”. En L. Dammert \& J. Bailey (coords.) Seguridad y reforma policial en las Américas: Experiencias y desafíos (pp. 5879). México: Siglo XXI. 
Hathazy, P. (2010). "Los caminos de la opacidad policial: accesibilidad y resistencia en el estudio de las organizaciones policiales como obstáculo y dato". En M. Sirimarco (comp.) Estudiar la policía: la mirada de las ciencias sociales sobre la institución policial (pp. 139-149). Buenos Aires: Teseo.

Hathazy, P. (2016). "La (re)militarización policial en la Argentina post-crisis: entre intereses organizacionales e instrumentalización política en los campos policiales". Dilemas. Revista de Estudos de Conflito e Controle Social, 9(1), 67-101. [Recuperado de: https://revistas.ufrj.br/index.php/dilemas/article/ view/7681]

Kahan, E. (2008). Unos pocos peligrosos sensatos. La Dirección de Inteligencia de la Policía de la provincia de Buenos Aires frente a las instituciones judías de la ciudad de La Plata. La Plata: EDULP.

Kahan, E. (2009). 'La argentinidad al palo: el 'registro', la 'vigilancia' y el 'control' efectuados por los agentes de la Dirección de Inteligencia de la Policía de la Provincia de Buenos Aires (DIPBA) sobre las instituciones judías de la ciudad de La Plata”, en Bohoslavsky, E., Caimari, L. \& Schettini, C. (orgs.) La policía en perspectiva histórica.

Maneiro, M. (2005). Como el árbol talado. Memorias del Genocidio en La Plata, Berisso y Ensenada. La Plata: Al Margen.

Marengo, E. (2015). Lo aparente como real. Un análisis del sujeto "comunista” en la creación y consolidación del servicio de inteligencia de la policía de la Provincia de Buenos Aires (1930-1962). La Plata-Los Polvorines-Posadas: UNLP/UNGS/ UNaM. [Recuperado de: http://www.libros.fahce.unlp.edu.ar/index.php/libros/ catalog/book/35]

Margaria, P. \& Schnyder, C. (2017). "La política bajo sospecha. Regularidades y reformulaciones de la vigilancia política en Argentina: la policía de Santiago del Estero". Nuevo Mundo Mundos Nuevos. [Recuperado de: http://journals. openedition.org/nuevomundo/68129?lang=pt.]

Mazzei, D. (2012). Bajo el poder de la caballería. El Ejército argentino (1962-1973). Buenos Aires: Eudeba.

Merele, H. (2017). La “depuración ideológica” del peronismo en el Partido de General Sarmiento (1973-1974). Una aproximación al proceso represivo durante los años setenta constitucionales a partir del caso de Antonio “Tito” Deleroni. La Plata Los Polvorines - Posadas: UNLP - UNGS - UnaM. [Recuperado de: http:/www. libros.fahce.unlp.edu.ar/index.php/libros/catalog/book/88]

Montero, A. (2007). "Policía y violencia. Apuntes comparativos sobre el lugar de la fuerza física en la definición del objeto de la "sociología de la policía", en Revista Delito y Sociedad, 1(23), 59-88, Recuperado de: http://bibliotecavirtual.unl.edu. ar/ojs/index.php/DelitoYSociedad/article/view/5331/8019.

Montero, L. (2016). "El rol de la "comunidad informativa" en la represión en Bahía Blanca (1975-1977): prácticas, acuerdos y disputas". En G. Águila, S. Garaño \& P. Scatizza (coords.) Represión estatal y violencia paraestatal en la historia reciente argentina (pp. 367-394)... 
Águila. Policías, represión y "lucha antisubversiva": exploraciones sobre el rol de las policías en el accionar...

Muzzopappa, E. (2017) "Militarización sin militares. Policías en tiempos de guerra", en Pérez, P. et al., Dossier "La formación policial en Río Negro". [Recuperado de: http://publicaciones.sociales.uba.ar/index.php/cuadernosdemarte/article/ view/2673/2296]

Nemec, D. (2017). "Los pueblos construidos durante el 'Operativo Independencia'. Castigar, controlar y convencer en el sudoeste tucumano (1976-1977)". XVI Jornadas Interescuelas/Departamentos de Historia, Universidad Nacional de Mar del Plata.

Olmo, D. (2002). "Reconstruir desde fragmentos. El uso de archivos policiales en la antropología forense en Argentina". En L. da Silva Catela \& E. Jelin (comps.) Los archivos de la represión: documentos, memoria y verdad (pp. 179-194). Madrid: Siglo XXI.

Paiaro, M. (2010). El poder desaparecedor en Córdoba. 1974-1976. Las formas institucionales y no institucionales del aparato represivo (Tesis de Licenciatura), mimeo.

Paiaro, M. (2015). "Entre "actitudes sospechosas" y "disparos intimidatorios": el relato policial en los libros de guardia del Comando Radioeléctrico en los años '70". Etnográfica, 19 (3), 441-461. [Recuperado de: http://journals.openedition.org/ etnografica/4062]

Palmieri, G., Martínez, J., Sozzo, M. \& Thomas, H. (2001). "Mecanismos de control interno e iniciativas de reforma en las instituciones policiales argentinas. Los casos de la Policía Federal Argentina, la Policía de la Provincia de Santa Fe y la Policía de la Provincia de Buenos Aires". En H. Früling \& A. Candina (eds.) Policía, Sociedad y Estado: Modernización y Reforma Policial en América del Sur (pp. 177-220). Santiago de Chile: CED.

Pérez, P. (2009). "Las policías fronterizas: mecanismos de control y espacialización en los territorios nacionales del sur a principios del siglo XX". XII Jornadas Interescuelas/Departamentos de Historia, Universidad Nacional del Comahue. [Recuperado de: http://cdsa.aacademica.org/000-008/292]

Pérez, P. et al. (2017). Dossier "La formación policial en Río Negro", Cuadernos de Marte. Revista latinoamericana de sociología de la guerra, XIII. [Recuperado de: http://publicaciones.sociales.uba.ar/index.php/cuadernosdemarte/issue/ current/showToc].

Pontoriero, E. (2015). "La seguridad interna como teatro bélico: legislación de defensa y contrainsurgencia en la Argentina (1966-1973)". A Contracorriente, 13(1) [Recuperado de: https://acontracorriente.chass.ncsu.edu/index.php/ acontracorriente/article/view/1288]

Pontoriero, E. (2016). "«Preparativos de guerra»: Ejército, doctrina antisubversiva y planes represivos en los orígenes el terror de Estado, 1973-1976". Revista Universitaria de Historia Militar, 5(10), 319-339. [Recuperado de: http://ruhm. es/index.php/RUHM/article/view/226/197]

Pontoriero, E. (2016). "De la guerra (contrainsurgente): la formación de la doctrina antisubversiva del Ejército argentino (1955-1976)". En G. Águila, S. Garaño 
\& P. Scatizza (coords.) Represión estatal y violencia paraestatal en la historia reciente argentina... (pp. 44-68)

Rafart, G. (2008). Tiempo de violencia en la Patagonia. Bandidos, policías y jueces, 1890-1940. Buenos Aires: Prometeo.

Regueiro, S. (2013). Apropiación de niños, familias y justicia. Argentina (1976-2012). Rosario: Prohistoria.

Ríos, A. L. (2014). "Estudiar lo policial. Consideraciones acerca del estudio de las fuerzas de seguridad y una apuesta”. Sociológica, 29(81), 87-118. [Recuperado de: http://www.redalyc.org/articulo.oa?id=305031176003]

Robles, M. (2010). La búsqueda. Una entrevista con Charlie Moore, Córdoba: Ediciones del pasaje.

Rodríguez Agüero, L. (2009). "Mujeres en situación de prostitución como blanco del accionar represivo: el caso del Comando Moralizador Pío XII, Mendoza, 1974-1976". En A. Andújar et al. De minifaldas, militancias y revoluciones. Exploraciones sobre los 70 en Argentina (pp. 109-126). Buenos Aires: Luxemburg. Rosignoli, B. (2014). Desentrañando el despliegue territorial del terrorismo de Estado. Un estudio espacial acerca de las estrategias de disposición final instrumentadas sobre el sur santafesino (1973-1983) (Tesis de Licenciatura), mimeo.

Saín, M. (1997). "Condiciones institucionales del control parlamentario de las actividades y organismos de inteligencia del Estado". Control Democrático de los organismos de seguridad interior en la República Argentina (pp. 140-176), Documentos de Trabajo-Centro de Estudios Legales y Sociales (CELS).

Saín, M. (2008). El Leviatán Azul. Política y Policía en Argentina. Buenos Aires: Siglo XXI.

Sarrabayrouse Oliveira, M. J. (2011). Poder Judicial y Dictadura. El caso de la Morgue. Buenos Aires: CELS/Editores del Puerto.

Scatizza, P. (2015). “Un Comahue no tan frío. La Norpatagonia argentina en el proyecto represivo de la dictadura militar(1975-1983)". Izquierdas, 23, 44-65. [Recuperado de: http://www.izquierdas.cl/96-2015/101-numero-23-abril-2015]

Scatizza, P. (2017). "Autonomía y sistematicidad del dispositivo represor. La Policía Federal en Neuquén (1975-1978)". Páginas. Revista digital de la Escuela de Historia, 9(21), 152-174. [Recuperado de http://revistapaginas.unr.edu.ar/index. $\mathrm{php} /$ RevPaginas/article/view/276/356]

Sirimarco, M. (comp.). 2010. Estudiar la policía: la mirada de las ciencias sociales sobre la institución policial. Buenos Aires: Teseo.

Sirimarco, M. (2009). "El abordaje del campo policial. Algunas consideraciones en torno a la formación inicial: entre la praxis y las reformas". Jurídicas, 6(2), 123 139. [Recuperado de: http://132.248.9.34/hevila/JuridicasManizales/2009/vol6/ no2/7.pdf]

Solís, A. C. \& Ponza, P. (comps.). (2016). Córdoba a 40 años del golpe: estudios de la dictadura en clave local. Córdoba: Editorial UNC. [Recuperado de: https://ffyh.unc.edu.ar/editorial/wp-content/uploads/sites/5/2013/05/ EBOOK_40A\%C3\%91OSGOLPE.pdf] 
Sozzo, M. (ed.). (2005). Policía, violencia, democracia. Ensayos sociológicos. Santa Fe: Editorial UNL.

Sozzo, M. (2016). “¿Legados dictatoriales? Instituciones y prácticas policiales entre pasado y presente en América del Sur". Civitas, 16(4), 552-574. [Recuperado de: http://revistaseletronicas.pucrs.br/ojs/index.php/civitas/article/view/24547]

Tiscornia, S. (2000). "Violencia policial, derechos humanos y reformas policiales", en Delito y Sociedad, 1(14), 9-22. [Recuperado de: http://bibliotecavirtual.unl.edu. ar/ojs/index.php/DelitoYSociedad/article/view/5835]

Tiscornia, S.(comp.).(2004a). Burocraciasy violencia. Estudios de antropologíajurídica, Buenos Aires: Antropofagia. [Recuperado de: http://www.antropojuridica.com. ar/wp-content/uploads/2012/02/BurocraciasyViolencia.pdf]

Tiscornia, S. (2004b). "Entre el imperio del Estado de policía y los límites del derecho. Seguridad ciudadana y policía en Argentina”, Nueva Sociedad, 191, 78-89. [Recuperado de: http://nuso.org/media/articles/downloads/3197_1.pdf.]

Tschopp, H. A. (2001). Normativa policial de la provincia de Santa Fe. Buenos Aires: Rubinzal-Culzoni eds.

Villalta, C. (2012). Entregas y secuestros. El rol del Estado en la apropiación de niños. Buenos Aires: CELS/Editores del Puerto. 